\title{
EVALUATION OF THE EFFECTIVENESS OF TOPICAL EMLA CREAM AS LOCAL ANAESTHETIC IN VENEPUNCTURE
}

\author{
Bodicherla Siva Kumar1, Sampathi Shiva Krishna², Adil Hasan ${ }^{3}$
}

${ }^{1}$ Assistant Professor, Department of Anaesthesia, Malla Reddy Institute of Medical Sciences, Hyderabad.

${ }^{2}$ Senior Resident, Government Medical College, Nizamabad.

${ }^{3}$ Senior Resident, Department of Anaesthesia, Kamineni Institute of Medical Sciences, Narketpally.

\begin{tabular}{l}
\hline ABSTRACT \\
BACKGROUND AND OBJECTIVES \\
The efficacy of a topical anaesthetic formulation, EMLA 5\% cream (Eutectic Mixture of Local Anaesthetics) in obtunding the \\
pain produced by intravenous cannulation was determined in our study. This study aims at evaluating the efficacy of EMLA cream \\
in producing dermal analgesia for venous cannulation and the effect of timing of application of EMLA cream prior to cannulation.
\end{tabular}

\section{MATERIALS AND METHODS}

Amongst 60 patients, EMLA cream was applied for 60 minutes in 20 patients, 30 minutes in another 20 and in the remaining 20 no cream or placebo was applied.

\section{RESULTS}

Pain was assessed in all the groups by a 4-point rank score. It was found that patients with EMLA cream had lower pain scores and decreased haemodynamic stress response to venous cannulation when compared to the control group.

\section{INTERPRETATION AND CONCLUSION}

Maximum analgesia was observed in patients who had EMLA cream applied for 60 minutes. No significant side effects were seen with this formulation.

\section{KEYWORDS}

EMLA Cream, Venous Cannulation, Pain Score.

HOW TO CITE THIS ARTICLE: Kumar BS, Krishna SS, Hasan A. Evaluation of the effectiveness of topical EMLA cream as local anaesthetic in venepuncture. J. Evolution Med. Dent. Sci. 2016;5(38):2314-2318, DOI: 10.14260/jemds/2016/538

\section{INTRODUCTION}

One of the most important pre-requisites of delivering anaesthesia to any patient is securing a safe and patent intravenous access for drug and fluid administration. Intravenous cannulation is now performed almost universally before induction of anaesthesia. ${ }^{1}$

Superficial venous puncture in adults is performed currently without anaesthesia, as it is considered to be a less traumatic experience for them when compared to children. However, this procedure has been reported to produce significant pain. ${ }^{2}$ and therefore the use of percutaneous anaesthetic agents may be appropriate.

The needle prick can also make a patient uncooperative and the anxiety caused can result in an haemodynamic stress response leading to increase in heart rate and blood pressure of the patient. 3

Many attempts have been made to produce local analgesia and to allow painless venepuncture by the topical application of various drugs. Topical $4 \%$ lignocaine or $20 \%$ benzocaine have been employed but their use has been limited by concerns about local irritation, systemic toxicity and inadequate analgesia. ${ }^{4}$

Financial or Other, Competing Interest: None.

Submission 01-04-2016, Peer Review 23-04-2016,

Acceptance 29-04-2016, Published 12-05-2016.

Corresponding Author:

Bodicherla Siva Kumar

Assistant Professor,

Department of Anaesthesia,

Malla Reddy Institute of Medical Sciences,

Suraram Main Road,

Hyderabad-500055.

E-mail: avis_dr@yahoo.com

DOI: $10.14260 /$ jemds $/ 2016 / 538$
Other methods like use of ethyl chloride spray. ${ }^{5}$ lignocaine iontophoresis. ${ }^{6}$ and topical application of Ibuprofen. ${ }^{7}$ have been described, but each one has certain drawbacks.

The relative ineffectiveness of various transfer preparations have been attributed either to insufficient concentration of uncharged base of the anaesthetic product or to poor skin absorption.

With the advent of Eutectic Mixture of Local Anaesthetics (EMLA) cream, effective topical analgesia of intact skin is now claimed to be feasible without the need for subcutaneous injections or exposure to high concentrations of local anaesthetics. ${ }^{8}$

EMLA cream is a $1: 1 \%$ oil in water emulsion of $2.5 \%$ lignocaine and $2.5 \%$ prilocaine bases. This mixture is termed eutectic, as it has a melting point lower than its individual components. This mixture is liquid at room temperature, while individual components are crystalline substances. ${ }^{9}$

\section{AIM}

This study aims at evaluating the efficacy of EMLA cream in producing dermal analgesia for venous cannulation and the effect of timing of application of EMLA cream prior to cannulation.

\section{MATERIALS AND METHODS}

A total of 60 inpatients posted for elective surgeries belonging to ASA grade I and grade II were selected. The patients belonged to either sex and were of the age group 18 to 60 years. The study was conducted in Malla Reddy Institute of Medical Sciences, Hyderabad, over a period of one year. 
A Routine Pre-Operative Evaluation was done for all Patients and the Following Patients Were Excluded

- Patients with known hypersensitivity to EMLA cream or any other local anaesthetic,

- Patients with methaemoglobinaemia or on drugs that may cause methaemoglobinaemia,

- Patients with history of atopy,

- Patients with open wounds on dorsum of hand,

- Pregnant and lactating patients.

Investigations included routine haemogram, urine analysis, blood sugar and other specific tests as required for respective surgeries.

The purpose and procedure of the study was explained and informed consent was obtained from all patients.

\section{PROCEDURE}

The Patients were divided into three Groups Chosen at Random

- Group A- Study Group I.

- Group B- Study Group II, Group C- Control group.

- Group A- This group included 20 patients in whom EMLA cream was applied 30 minutes prior to venous cannulation.

- Group B- This group included 20 patients in whom EMLA cream was applied 60 minutes prior to venous cannulation.

- Group C- This group included 20 patients in whom venous cannulation was performed without EMLA cream, placebo or any occlusive dressing.

After explaining the procedure, non-dominant hand (Unless otherwise specified) was chosen and a suitable vein on the dorsum of the hand was selected.

In group $\mathrm{C}$ patients, intravenous cannulation was performed with 18-gauge IV cannula and pain score was noted. Heart rate and blood pressure were recorded before and during cannulation.

In group A and B patients, EMLA cream 1.5 to $2 \mathrm{gm} / 10$ $\mathrm{cm}^{2}$ area was applied over the site of cannulation in a thick layer. This layer was then covered with an occlusive dressing. The surrounding area was cleaned with dry gauze. EMLA cream was applied for 30 minutes in group A patients and 60 minutes in group B patients.

After the prescribed time of application of EMLA cream, the occlusive dressing was removed. The area was then wiped dry with gauze and observed for signs of any local reaction. After disinfecting with spirit, IV cannulation was performed with 18-gauge IV cannula and pain score noted. Heart rate and blood pressure recorded before and during cannulation.

Pain score was Graded using the 4-point scale (BJA 1994). ${ }^{1}$ as shown below
1. No pain
2. Mild facial grimace
3. Verbal response
4. Withdrawal of hand

This pain score was graded by an independent observer blinded only with respect to time of application of EMLA cream.

\section{STATISTICAL ANALYSIS}

The results were presented as mean, standard deviation, numbers and percentages. Inferential analysis was performed using Chi-square test. A two tailed p-value $<0.05$ was considered as statistically significant.

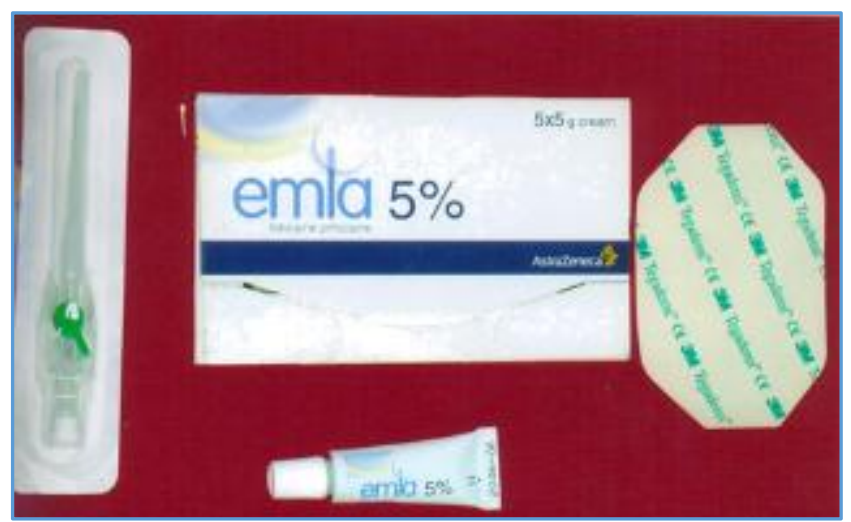

18-G IV Cannula, EMLA Cream and Occlusive Dressing

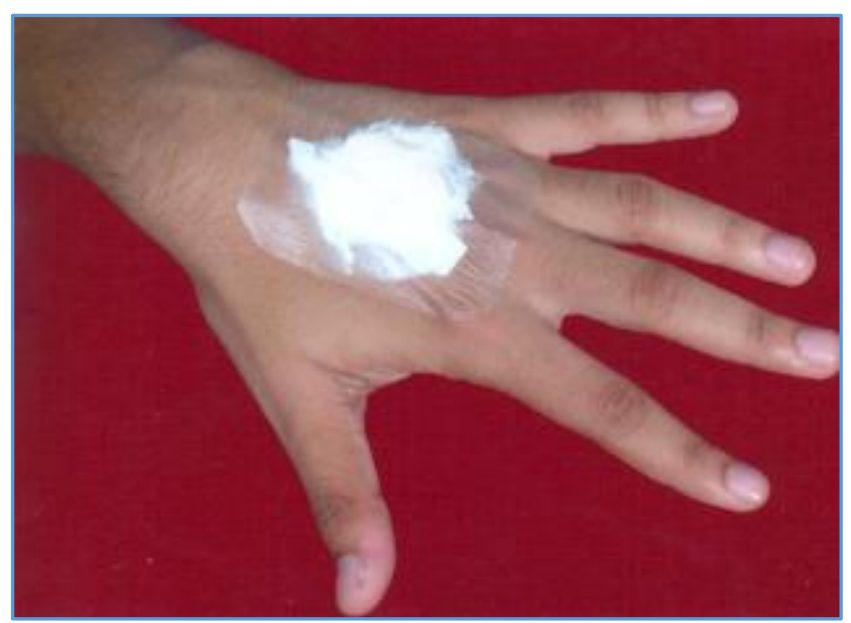

Application of EMLA Cream Prior to Venous Cannulation

\section{OBSERVATION AND RESULTS}

Sixty patients belonging to the age group 18 to 60 years of either sex were selected for the study.

They were divided into 3 groups: Group A, Group B and Group C.

The 3 groups were compared with respect to weight, age, sex, length of application of EMLA cream, pain scoring and haemodynamic variables.

Only one patient in Group B had blanching as a side effect of EMLA application. No serious adverse reactions were seen in any of the patients.

\begin{tabular}{|c|c|c|c|c|c|}
\hline Group & $\begin{array}{c}\text { Min. } \\
\text { Wt. }\end{array}$ & $\begin{array}{c}\text { Max. } \\
\text { Wt. }\end{array}$ & Mean & $\begin{array}{c}\text { Std. } \\
\text { Deviation }\end{array}$ & 'p' \\
\hline $\begin{array}{c}\text { Group A } \\
\text { (30 min) }\end{array}$ & $30 \mathrm{~kg}$ & $90 \mathrm{~kg}$ & 55.3000 & 14.3897 & \\
\hline $\begin{array}{c}\text { Group B } \\
\text { (60 min) }\end{array}$ & $39 \mathrm{~kg}$ & $74 \mathrm{~kg}$ & 51.2500 & 7.5385 & 0.315 \\
\hline $\begin{array}{c}\text { Group C } \\
\text { (Control) }\end{array}$ & $45 \mathrm{~kg}$ & $84 \mathrm{~kg}$ & 56.4000 & 10.5252 & \\
\hline \multicolumn{6}{|c|}{ Table 1: Weight Distribution } \\
\hline
\end{tabular}

The 3 groups had higher number of patients weighing $50-60 \mathrm{~kg}$ and the ' $\mathrm{p}$ ' value was not significant. 


\begin{tabular}{|c|c|c|c|c|c|}
\hline Group & $\begin{array}{c}\text { Min. } \\
\text { Age }\end{array}$ & $\begin{array}{c}\text { Max. } \\
\text { Age }\end{array}$ & Mean & $\begin{array}{c}\text { Std. } \\
\text { Deviation }\end{array}$ & 'p' \\
\hline $\begin{array}{c}\text { Group A } \\
\text { (30 min) }\end{array}$ & $\begin{array}{c}18 \\
\text { yrs. }\end{array}$ & $\begin{array}{c}60 \\
\text { yrs. }\end{array}$ & 40.9500 & 13.7131 & \\
\hline $\begin{array}{c}\text { Group B } \\
\text { (60 min) }\end{array}$ & $\begin{array}{c}19 \\
\text { yrs. }\end{array}$ & $\begin{array}{c}55 \\
\text { yrs. }\end{array}$ & 34.1500 & 10.2201 & 0.214 \\
\hline $\begin{array}{c}\text { Group C } \\
\text { (Control) }\end{array}$ & $\begin{array}{c}18 \\
\text { yrs. }\end{array}$ & $\begin{array}{c}60 \\
\text { yrs. }\end{array}$ & 36.5000 & 12.6220 & \\
\hline \multicolumn{6}{|c|}{ Table 2: Age Distribution } \\
\hline
\end{tabular}

The 3 groups had higher number of patients within age group 30-40 yrs. with a non-significant 'p' value.

\begin{tabular}{|c|c|c|c|c|c|}
\hline & & & Group & & \\
\hline & Sex & Group A & Group B & Group C & Total \\
\hline F & Count & 10 & 11 & 9 & 30 \\
\hline & $\%$ & 50 & 55 & 45 & 50 \\
\hline M & Count & 10 & 9 & 11 & 30 \\
\hline & $\%$ & 50 & 45 & 55 & 50 \\
\hline \multicolumn{7}{|c|}{ Total Count } & $\mathbf{2 0}$ & $\mathbf{2 0}$ & $\mathbf{2 0}$ & $\mathbf{6 0}$ \\
\hline \multicolumn{7}{|c|}{ Table 3: Sex Distribution } \\
\hline
\end{tabular}

The 3 groups did not show any statistical difference with respect to sex distribution.

\begin{tabular}{|c|c|c|c|c|c|c|c|}
\hline Group & & \multicolumn{2}{|c|}{$\begin{array}{c}\text { Pain } \\
\text { Score }\end{array}$} & & Mean & $\begin{array}{c}\text { Std. } \\
\text { Deviation }\end{array}$ & 'p' \\
\hline & 0 & 1 & 2 & 3 & & & \\
\hline $\begin{array}{c}\text { Group } \\
\text { A }\end{array}$ & 1 & 11 & 8 & 0 & 1.35 & 0.5871 & \\
\hline $\begin{array}{c}\text { Group } \\
\text { B }\end{array}$ & 17 & 3 & 0 & 0 & 0.15 & 0.3663 & 0.001 \\
\hline $\begin{array}{c}\text { Group } \\
\text { C }\end{array}$ & 0 & 2 & 8 & 10 & 2.50 & 0.6070 & \\
\hline
\end{tabular}

\section{Table 4: Comparison of Pain Scoring During Cannulation}

0 -No pain; 1 -Mild facial grimace; 2 -Verbal response; 3 -Withdrawal of hand.

Pain score comparison among the 3 groups showed a highly significant change with the control group having highest mean pain score. Patients of group B (EMLA for 60 min) had lower pain scores when compared with patients of group A (EMLA for $30 \mathrm{~min}$ ).

\begin{tabular}{|c|c|c|c|c|c|c|c|}
\hline Cannulation & Group & Number & Min. & Max. & Mean & Std. Deviation & 'p' \\
\hline \multirow[t]{3}{*}{ Before } & Group A & 20 & 60 & 120 & 82.15 & 15.97 & \\
\hline & Group B & 20 & 64 & 110 & 83.00 & 11.96 & \\
\hline & Group C & 20 & 54 & 100 & 78.35 & 13.68 & 0.536 \\
\hline \multirow[t]{3}{*}{ During } & Group A & 20 & 65 & 128 & 87.25 & 17.61 & \\
\hline & Group B & 20 & 68 & 120 & 85.10 & 12.96 & \\
\hline & Group C & 20 & 58 & 130 & 88.35 & 17.81 & 0.814 \\
\hline
\end{tabular}

In all the groups, there was no significant change in heart rate but patients in the control group had a higher increase in heart rate when compared to the other 2 groups.

\begin{tabular}{|c|c|c|c|c|c|c|c|}
\hline Cannulation & Group & Number & Min. & Max. & Mean & Std. Deviation & 'p' \\
\hline & Group A & 20 & 100 & 160 & 120.55 & 14.96 & 10.98 \\
\hline & Group B & 20 & 100 & 140 & 117.30 & 0.012 \\
\hline & Group C & 20 & 110 & 150 & 129.10 & 11.02 & 15.67 \\
\hline & Group A & 20 & 107 & 164 & 126.60 & 11.42 & 0.001 \\
\hline & Group B & 20 & 100 & 140 & 117.60 & 11.15 & \\
\hline & Group C & 20 & 128 & 164 & 139.90 & \\
\hline
\end{tabular}

Patients in the control group had a significant rise in systolic blood pressure during cannulation.

\begin{tabular}{|c|c|c|c|c|c|c|c|}
\hline Cannulation & Group & Number & Min. & Max. & Mean & Std. Deviation & 'p' \\
\hline \multirow[t]{3}{*}{ Before } & Group A & 20 & 60 & 100 & 80.40 & 10.41 & \\
\hline & Group B & 20 & 70 & 80 & 74.80 & 4.96 & 0.02 \\
\hline & Group C & 20 & 70 & 90 & 81.30 & 6.66 & \\
\hline \multirow[t]{3}{*}{ During } & Group A & 20 & 60 & 100 & 82.20 & 10.42 & \\
\hline & Group B & 20 & 70 & 80 & 74.80 & 5.00 & 0.001 \\
\hline & Group C & 20 & 70 & 100 & 87.10 & 7.03 & \\
\hline
\end{tabular}

Patients in the control group had a significant rise in diastolic blood pressure during cannulation.

\section{DISCUSSION}

We have selected 60 patients of either sex belonging to the age group 18-60 years posted for elective surgeries. Pain score was assessed in these patients for IV cannulation by the 4-point rank score as per the study done by Molodecka J and Stenhouse C (1994). In 40 of the total patients, EMLA cream was applied prior to venous cannulation. The remaining 20 patients belonged to the control group. The groups were comparable regarding weight, age and sex and there were no statistical difference with respect to these variables. Each group had higher number of patients in the age group 30-40 years and with weight between $50-60 \mathrm{~kg}$.

Various studies have been done to show efficacy and timing of application of EMLA cream to provide dermal analgesia for IV cannulation. Molodecka J and Stenhouse C (1994) conducted a study wherein the efficacy of topical 
amethocaine cream was compared to 5\% EMLA cream in alleviating pain of venous cannulation.

Pain was assessed on a 4-point rank score. Good analgesia was obtained in all the groups. Similarly, we have also obtained reduced pain scores in the patients treated with EMLA cream prior to venous cannulation. Out of the 40 patients with EMLA cream application, 32 patients had lower pain scores of 0 and 1 ; whereas only 2 patients in the control group had low pain scores. Another study conducted by Wig J, Johl KS. ${ }^{10}$ (1990) also revealed reduced pain scores in 84\% of their subjects with EMLA cream prior to cannulation compared to $16 \%$ of the placebo group.

In our study, we had divided the 40 patients receiving EMLA cream into two groups A and B. Patients in group A had EMLA cream applied to them 30 minutes prior to cannulation and patients in group B 60 minutes prior to cannulation. Both the groups had reduced pain scores to IV cannulation, but patients in group B (i.e. 60 min of EMLA application time) had significantly lower pain scores as compared to group $A$.

The mean pain score obtained in group $B$ was 0.15 and in group A was 1.35; compared to control group of 2.5. This showed that EMLA cream application is probably effective after applying for half an hour, but for maximum analgesic effect it has to be applied an hour before. Hallen B, Olsson GC et al11 (1984) conducted a study to assess the effect of timing of application of EMLA cream and their study also revealed that the effect of cream became evident at about 60 minutes for venepuncture. But a similar study conducted by Ehrenstrom, Reiz G, Reiz S et al ${ }^{12}$ (1983) revealed a minimum effective application time of 45 minutes prior to IV cannulation, whereas MR Nott and JL Peacock.13 (1990) showed that EMLA cream had significantly less pain score after 5 minutes of EMLA cream application. Hopkins CS and Buckley CJ.14 (1988) conducted a study in children treated with EMLA cream prior to venous cannulation and lower pain scores were recorded in them. But their study did not reveal any variation in analgesia for application times between 30 minutes and 90 minutes.

Norbert Griessinger (1995) suggested that application of EMLA cream can be a very useful measure to facilitate venepuncture in patients with reflex sympathetic dystrophy as it avoids any haemodynamic alterations. Speirs AF, Taylor $\mathrm{KH}$, et al15 (2001) conducted a study of topical analgesics and it revealed that EMLA cream and Ametop produced effective skin analgesia for venous cannulation and that the use of topical analgesics reduced anxiety about future cannulation procedures. Heart rate, systolic blood pressure and diastolic blood pressure were recorded before and during cannulation in all our patients. We found that application of EMLA cream did not cause a significant rise in haemodynamic variables during cannulation when compared to the control group. The same finding was appreciated by Lindh et al16 (2000) that EMLA cream application decreased the stress response to venepuncture in new-born infants.

Many attempts have been made previously to provide analgesia to the skin. Monash S.17 (1957) have suggested preparations containing lignocaine for topical anaesthesia of the unbroken skin. Kligman. ${ }^{18}$ (1965) and Brechner, Cohen and Pretsky. ${ }^{19}$ (1967) suggested topical application of local anaesthetic mixtures with dimethyl sulphoxide (DMSO). Topical benzocaine was used in a study done by Dalili $\mathrm{H}$ and Adriani J.20 (1971). Russo et al21 (1980) did a study comparing physical methods, such as iontophoresis and injection of lignocaine for dermal analgesia. However, no formulation has gained wide acceptance mainly as a result of inadequate relief of pain, local irritation or toxic reactions.

\section{SUMMARY}

The efficacy of a topical anaesthetic formulation EMLA 5\% cream (Eutectic Mixture of Local Anaesthetics) in obtunding the pain produced by intravenous cannulation was determined in our study.

- Our study comprised of 60 patients of either sex belonging to ASA grade 1 and 2 .

- Patients belonged to the age group 18 - 60 years with higher number of patients within age $30-40$ years.

- Patients in whom EMLA was applied 60 minutes prior to cannulation had the lowest mean pain score value of 0.15 .

- The effective time of application of EMLA cream in producing adequate analgesia to venous cannulation was found to be 60 minutes.

- Patients in the control group had a significant haemodynamic stress response to venous cannulation when compared to patients with EMLA application.

\section{CONCLUSION}

In our study, we have proved that the application of EMLA cream for venous cannulation alleviated pain and also prevented a significant rise in blood pressure and heart rate. The effective time of application was found to be 60 minutes. EMLA cream has been found to be efficacious as a topical analgesic prior to venepuncture. The main advantage being in its single dosage and easy application without distorting anatomical landmarks. The minor disadvantages include cost of EMLA cream. The cost factor could be overlooked considering the efficacy of EMLA cream in producing dermal analgesia especially in children, anxious adults and in patients exposed to repeated venepuncture.

We therefore recommend the use of EMLA cream prior to venepuncture in all patients.

\section{REFERENCES}

1. Molodecka J, Stenhouse C, Jones JM, et al. Comparison of percutaneous anaesthesia for venous cannulation after topical application of either amethocaine or EMLA cream. British Journal of Anaesthesia 1994;72(2):174-6.

2. Harrison N, Langham BT, Bogod DG. Appropriate use of local anaesthetic for venous cannulation. Anaesthesia 1992;47(3):210-2.

3. Griessinger N, Sittl R. EMLA cream for venepuncture in patients with reflex sympathetic dystrophy. Anaesthesia Analgesia 1995;81(2):432-3.

4. Maddi R, Horrow JC, Mark JB, et al. Evaluation of a new cutaneous topical anaesthesia preparation. Regional Anaesthesia 1990;15(3):109-12.

5. Armstrong P, Young C, McKeown D. Ethyl chloride and venepuncture pain; a comparison with intradermal lidocaine. Canadian Journal of Anaesthesia 1990;37(6):656-8.

6. Moppett IK, Szypula K, Yeoman PM. Comparison of EMLA and lidocaineionotrophoresis for cannulation analgesia. Eur J Anaesthesiol 2004;21(3)210-3. 
7. Smith AJ, Stacey MR. Topical ibuprofen for skin analgesia prior to venepuncture. Anaesthesia 1996;51(5):495-7.

8. Noor M Gajraj, John H Penant, Watcha MF. Eutectic mixture of local anaesthetic (EMLA cream). Anaesthesia Analgesia 1994;78(3):574-83.

9. Nyquist-Mayer A, Brodin A, Franks S. Drug release studies on an oil-water emulsion based on a eutectic mixture of lidocaine and prilocaine as the dispersed phase. J Pharm Sci 1986;75(4):365-73.

10. Wig J, Johl KS. Ourexperince with EMLA cream (for painless venous cannulation in children). Indian Journal of Physiology and Pharmacology 1990;34(2):130-2.

11. Hallen B, Olsson G, Uppfeldt A. Painfree venepuncture. Effect of timing of application of local anaesthetic cream. Anaesthesia 1984;39(10):969-72.

12. Ehrenstrom Reiz G, Reiz S, Stockman O. Topical anaesthesia with EMLA, a new lidocaine-prilocaine cream and the cusum technique for detection of minimal application time. Acta Anaesthesiol Scand 1983;27(6):510-2.

13. Nott MR, Peacock JL. Relief of injection pain in adults. EMLA cream for 5 minutes before venepuncture. Anaesthesia 1990;45(9):772-4.

14. Hopkins CS, Buckley CJ, Bush GH. Pain free injection in infants. Use of a lignocaine-prilocaine cream to prevent pain at intravenous induction of general anaesthesia in 1-5 year old children. Anaesthesia 1988;43(3):198-201.
15. Speirs AF, Taylor $\mathrm{KH}$, Joanes DN, et al. A randomized double blind, placebo-controlled, comparative study of topical skin analgesia and the anxiety and discomfort associated with venous cannulation. $\mathrm{Br}$ Dent J 2001;190(8):444-9.

16. Lindh V, Wiklund U, Hakansson S. Assessment of the effect of EMLA cream during venepuncture in the new born by analysis of heart rate variability. Pain 2000;86(3):247-54.

17. Monash S. Topical anaesthesia of the unbroken skin. AMA Arch Dermatol 1957;76(6):752-6.

18. Kligman AM. Topical pharmacology and toxicology of dimethyl sulphoxide. JAMA 1965;193:796-804.

19. Brechner VL, Cohen DD, Pretsky I. Dermal anaesthesia bu the topical application of tetracaine base dissolved in dimethyl sulphoxide. Ann N Y Acad Sci 1967;141:52431.

20. Dalili H, Adriani J. The efficacy of local anaesthetics in blocking the sensation of itch, burning and pain in normaland sunburned skin. Clin, Pharmcol, Ther 1971;12(6):913-9.

21. Russo J, Lipman AG, Comstock TJ, et al. Lidocaine anaesthesia: comparison of ionto phoresis, injection and swabbing. Am J Hosp Pharm 1980;37(6):843. 